Revista de Estudios Histórico-Jurídicos

[Sección historia del derecho europeo]

XLIII (Valparaíso, Chile, 2021)

[pp. 241-261]

\title{
LA PROTECCIÓN DEL PROPIETARIO PRETORIO EN DERECHO CLÁSICO Y SU RECEPCIÓN EN EL CÓDIGO CIVIL ESPAÑOL
}

[The protection of the praetorian proprietor in the classical roman law and how it was received by the Spanish Civil Code]

\author{
Adolfo A. Díaz-Bautista Cremades* \\ Universidad de Murcia, España
}

\begin{abstract}
RESUMEN
Aunque pudiera imaginarse una organización social sin derecho de propiedad, no resulta posible suponer un estado sin posesión. Dado que en su origen la posesión no es más que el hecho de que una persona tenga físicamente una cosa en su poder, su imaginaria eliminación supondría la supresión de las cosas, ya que estas tienen relevancia jurídica en la medida en que podemos utilizarlas. Siendo una mera situación fáctica, muchas veces provisional, la posesión se ha convertido en uno de los problemas jurídicos más complejos de nuestro derecho privado. En particular, en este trabajo nos ocuparemos del caso de quien posee un bien a título de dueño por haberlo adquirido de quien parecía serlo y que, por distintas razones, no ha alcanzado a ser propietario. En estos supuestos, con ciertos requisitos, el derecho concede una protección especial al poseedor incluso por encima del verdadero propietario.
\end{abstract}

ABSTRACT

* Profesor contratado, Doctor, Universidad de Murcia, adiaz-bautista@um.es, ORCID 0000-0002-9234-6302, PUBLONS Z-4576-2019 
Palabras Clave

Posesión - propiedad - usucapión adquisición a non domino - actio publiciana.

\section{KeY Words}

Possession - ownership - usucapio acquisition a non domino - actio publiciana.

RECIBIDO el 5 de abril de 2020 y ACEPTADO el 9 de julio de 2021

\section{TENENCIA, POSESIÓN NATURAL Y POSESIÓN CIVIL}

Como es sabido, la institución de la posesión ha sufrido una enorme evolución a lo largo de la historia ${ }^{1}$, pasando de describir la mera tenencia física de una cosa hasta referirse a cualquier situación en que una persona, de manera legítima o ilegítima, tiene a su disposición, física o jurídicamente, un bien; lo cual obliga a la doctrina a establecer categorías y clases de poseedores. Sin embargo, el conocido rechazo de los juristas clásicos a la dogmática y a la abstracción, dificulta la tarea de reconducir las previsiones de los jurisconsultos a conceptos modernos. Asimismo, la evolución de esta figura a lo largo del derecho clásico y postclásico debe alertarnos a la hora de tomar la información que recibimos de las fuentes justinianeas ${ }^{2}$. Serán, por tanto, los tratadistas del mos gallicus y posteriormente los estudiosos de los siglos XIX y XX quienes establecerán, de manera más o menos uniforme, las bases de la ciencia moderna sobre elementos del derecho clásico, por lo que, a la hora de estudiar este, debemos tomar con precaución la taxonomía moderna.

Esta clasificación se realiza habitualmente tomando en cuenta tres elementos: la tenencia física de la cosa, también llamado corpus de la posesión, el título de posesión, que podría identificarse con el animus possessionis ${ }^{3}$, y la buena o mala fe del poseedor, entendida como credibilidad objetiva del título de posesión. A ello podríamos añadir un cuarto criterio constituido por la legitimidad o ilicitud del hecho posesorio.

Conjugando todos estos elementos, la doctrina moderna ha elaborado una

${ }^{1}$ Lacruz Berdejo, José Luis, Elementos de derecho civil, III: Derechos reales (Barcelona, 1990), p. 31. En el mismo sentido, Panero Gutiérrez afirma que, "si es difícil imaginar una sociedad en la que $\mathrm{n}$ a d a sea de $\mathrm{n}$ a di e, lo es, aún más, imaginar otra en la que $\mathrm{n}$ a d i e te $\mathrm{ng}$ a n a d a . Panero Gutiérrez, Ricardo, Derecho romano (Valencia, Tirant, 1997), p. 355.

${ }^{2}$ Advierte D'Ors de que en derecho vulgar la propiedad se confunde con la posesión, hasta tal punto que la distinción se bubiera perdido de no serpor el esfuerzo clasicista de Justiniano. D’ORs, Álvaro: Derecho privado romano (Pamplona, EunsA, 1989), p. 188.

${ }^{3}$ A pesar de lo que la literalidad del término pudiera sugerir, el animus no es la intención con que el sujeto posee la cosa sino el título que pretende o afirma tener sobre la misma, la manera en que se presenta ante la sociedad en relación con la cosa. Dicho título puede ser o no existente, lo que dará lugar a la licitud o ilicitud de la posesión, pero, sobre todo, lo que mayor trascendencia jurídica tendrá sobre el régimen de la posesión, el sujeto puede tener o no conciencia de la inexistencia del título -en su caso- y ello determinará que sea un poseedor de buena o de mala fe. 
serie de conceptos que permiten establecer distintos regímenes jurídicos para diferentes supuestos ${ }^{4}$.

\section{Poseedor natural}

Aquella persona que ostenta el poder físico sobre la cosa, pero sabe y reconoce que carece de propiedad sobre el mismo es denominado, modernamente, poseedor natural. Como no afirma ser propietario, no crea una apariencia jurídica de propiedad que induzca a confusión y deba ser, en su caso, reconocida, por lo que nunca adquirirá -por el mero hecho de ser poseedor- el dominio sobre el bien.

Sin embargo, eso no significa que el poseedor natural no tenga ninguna protección jurídica. El hecho de serlo, tanto si es de buena como si es de mala fe, le da derecho a no ser despojado por la fuerza. Es decir, todo poseedor ${ }^{5}$, aunque solo ostente el corpus, tiene el derecho a seguir poseyendo (ius possesionis), que el ordenamiento jurídico protege a través de los interdictos ${ }^{6}$.

\section{Detentador}

Por razones desconocidas, probablemente de origen histórico y socioeconómico, algunos sujetos que tenían corpus sobre un bien no eran reconocidos como poseedores y, por tanto, carecían de la protección interdictal. Son los llamados

\footnotetext{
${ }^{4}$ Seguimos en el presente trabajo la clasificación establecida por Díaz Bautista. La romanística en general no asume las categorías expuestas, sino que encuadra los mismos casos descritos en la siguiente clasificación: -Poseedores naturales: aquellos que carecían de protección interdictal (arrendatarios, depositarios judiciales y ordinarios, comodatarios y usufructuarios), a los cuales nosotros hemos llamado d e t e n t a d o r e s - Poseedores civiles: Aquellos que poseen con un título distinto del de propietario y gozan de la protección interdictal (precaristas, acreedores pignoraticios, etc.). En nuestra clasificación, acomodada a derecho moderno, los hemos denominado p o s e ed ores n a t u ra les. Según la doctrina mayoritaria, estos son llamados simplemente p o s e e d o r e s . - Poseedores ad usucapionem: Quienes poseen a título de dueño, tengan o no título válido y sean o no de buena fe. Aquí se incluirían los poseedores civiles de nuestra clasificación y los auténticos poseedores ad usucapionem o propietarios pretorios. CASTÁN, por su parte, clasifica las situaciones posesorias, con referencia a las fuentes, en: natural (desprovista de protección interdictal) civil (con animus domini) e interdictal, que engloba aquellas situaciones en que el sujeto posee sin apariencia de dominio, pero con protección pretoria. En realidad, la disputa, puramente taxonómica, se refiere a la dificultad de encajar en un esquema lógico la concurrencia de detentadores y poseedores naturales cuando se advierte que no existe una razón dogmática para tal distinción y que el hecho de que unos gozasen de la protección pretoria y otros no tan solo obedece a criterios históricos o socioeconómicos, pero no conceptuales o de equidad. En nuestro caso optamos por englobar los supuestos desprovistos de interdictos en una categoría excepcional llamada d e t e n t a d o r e s, manteniendo la denominación de p o s e e d o r n a t u r a l para todo aquel que posee (y es protegido) sin animus domini, reservando la categoría de p o s e e d o r c i v i l a quien posee como propietario, que a su vez puede ser pos e e d or ad us u capion e $m$ si reúne los requisitos de buena fe y justo título. Vid. Díaz Bautista, Antonio y Díaz-Bautista Cremades, Adolfo Antonio, El derecho romano como introducción al derecho ( $3^{\mathrm{a}} \mathrm{ed}$, Murcia, 2019), pp. 166 ss. En sentido contrario, Castán Pérez Gómez, Santiago, Derecho privado romano (Madrid, 2018), p. 131.

${ }^{5} \mathrm{El}$ punto de discusión podría ser, como se explicará más adelante, si quien adquiere de manera totalmente ilegítima, usando la fuerza, es, jurídicamente, un poseedor.

${ }^{6}$ En sentido contrario, vid. nota supra.
} 
detentadores ${ }^{7}$, un grupo heterogéneo formado por depositarios ordinarios, arrendatarios, depositarios de embargos provisionales, missi in possessionem res servandae gratia, comodatarios e incluso usufructuarios, a los que posteriormente se concedió el interdicto uti possidetis utilis ${ }^{8}$.

Estos tenedores carecían de ius possessionis y por tanto, si eran perturbados o despojados de su tenencia debían requerir a aquel de quien habían recibido el bien para que protegiera su situación.

En las Instituciones de Justiniano se explica esta privación de la posesión a inquilinos y colonos al considerar que estos detentadores poseen para otro, el arrendador, quien retiene la posesión con solo el animus, evitando así una eventual duplicidad de posesiones entre arrendador y arrendatario. Inst. 4,15,5: "Possidere autem videtur quisque non solum, si ipse possideat, sed et si eius nomine aliquis in possessione sit, licet is eius iuri subiectus non sit, qualis est colonus et inquilinus: per eos quoque apud quos deposuerit quis aut quibus commodaverit ipse possidere videtur: et hoc est quod dicitur, retinere possessionem posse aliquem per quemlibet qui eius nomine sit in possessione. quin etiam animo quoque retineri possessionem placet, id est ut quamvis neque ipse sit in possessione neque eius nomine alius, tamen si non relinquendae possessionis animo, sed postea reversurus inde discesserit, retinere possessionem videatur. adipisci vero possessionem per quos aliquis potest, secundo libro exposuimus. nec ulla dubitatio est quin animo solo possessionem adipisci nemo potest'.

Esta discriminación de algunos poseedores naturales, que como queda dicho, se basaba en razones históricas y no dogmáticas, quedó superada con la promulgación del Código Civil español, cuyo artículo 446 proclama que "Todo poseedor tiene derecho a ser respetado en su posesión $[. . .]^{\text {'? }}$.

\section{Poseedor civil}

La moderna doctrina denomina poseedor civil a quien no solo tiene el corpus de la posesión ${ }^{10}$ sino también actúa y se presenta ante la sociedad como verdadero propietario, es decir, tiene corpus y animus. En este caso se encuentran los propietarios, que no sólo detentan el dominio, sino que además actúan como tales, pero

${ }^{7}$ Aún el Código Civil español utiliza a menudo la expresión "mero tenedor" para referirse al poseedor natural (art. 463), aunque ahora ya sí dispone de protección interdictal.

${ }^{8}$ Pese a los sutiles esfuerzos de la Pandectística, al tratar de diferenciar entre la verdadera possessio y la mera detentación, y delimitar la figura del Besitzdiener (servidor de la posesión), no parece que tengamos una explicación convincente de por qué en Roma se consideró possessores a quienes poseían como propietarios, a los vectigalistas (más tarde convertidos en enfiteutas), a los precaristas, a los depositarios de embargos definitivos (missi in possessionem rei retinendae gratia, o missi in bona), y a los secuestratarios, negándoles, sin embargo, esta cualidad a los comodatarios, depositarios ordinarios, depositarios de embargos provisionales (missi in possessionem rei servandae gratia) usufructuarios y arrendatarios. Quizás la razón de esta limitación en el círculo de los poseedores protegidos se deba exclusivamente a vicisitudes históricas, pero buena prueba de que los juristas romanos tuvieron consciencia de su arbitrariedad la tenemos en la concesión del interdicto utrubi a los usufructuarios de muebles y del uti possidetis utilis a los de inmuebles.

${ }^{9}$ Aunque, como veremos más adelante, quizás la intención originaria del Código Civil español no era conceder la protección interdictal a todo el que tuviera la cosa en su poder.

${ }^{10}$ Stricto sensu no es necesario el corpus para predicar la posesión, dado que se reconocen situaciones como la posesión mediata y el servidor de la posesión, por lo que bastaría el animus para retener, jurídicamente, la posesión. 
también aquellos que -siendo o no conscientes de su falta de titularidad-actúan como si fueran propietarios.

El simple hecho de que un poseedor tenga animus domini no le confiere, per se, una mayor protección que la interdictal, que abarca, como ya se dijo, en nuestra opinión, a todo poseedor de buena y de mala fe. Sin embargo, en muchos casos, los poseedores civiles estarán incluidos en la siguiente categoría.

\section{Poseedor 'ad usucapionem'}

El poseedor civil no es más que aquel que afirma y se presenta ante la sociedad como propietario de un bien. Ab initio, ello no prejuzga que dicho poseedor sea de buena o de mala fe, ni que ostente un título válido que le permita acceder al dominio. Ni que tal título sea o no eficaz. Dicho en otras palabras: la categoría de poseedor civil abarca tanto al verus dominus, como al "okupa" que, consciente de la ilicitud de su acción, rompe la cerradura y se apropia de un inmueble ajeno, negando el derecho de su propietario.

Sin embargo, en esta nueva categoría que denominamos poseedor ad usucapionem encuadramos un cierto tipo concreto de poseedor civil: aquel que, además de afirmar que es propietario, ostenta un título de propiedad válido, en cuya eficacia puede confiar conforme a las circunstancias del tráfico jurídico común (bona fides). Se trata por tanto de un poseedor civil cualificado que se sabe propietario y se encuentra en tal circunstancia que cualquier bonus pater familias se consideraría propietario.

Este poseedor civil ad usucapionem, que en Roma fue llamado propietario pretorio ${ }^{11}$ mereció en derecho clásico una protección jurídica especial por cuanto, si resultaba vencido en una acción reivindicatoria, la discrepancia entre la realidad jurídica y la apariencia podría resultar especialmente injusta. Por ello, el legislador, en ciertos casos, opta por inclinar la balanza, despojando al verus dominus de su derecho vigente y atribuyendo la propiedad -o algo muy parecido- al poseedor. Dedicaremos a ello el resto de nuestro trabajo.

\section{LA PROPIEDAD PRETORIA ${ }^{12}$}

Queda por tanto concretado el supuesto fáctico que analizamos en el presente trabajo, conforme a las anteriores líneas, en aquel sujeto que posee como dueño una cosa ajena, ostentando un justo título válido pero ineficaz $z^{13}$, que el poseedor

${ }^{11}$ D’Ors lo define como “aquella situación en la que el Pretor defiende al que recibió una cosa mancipable contra el mismo propietario civil que se la entregó y no transmitió en la forma exigida para dar la propiedad civil; también cuando protege a alguien como si fuera propietario contra todos menos contra el propietario civil" (adquirente a non domino). D'Ors, Álvaro, cit. (n. 2), p. 187.

${ }^{12}$ Propiedad pretoria y propiedad bonitaria son términos equivalentes para la mayoría de la doctrina. Vid. en sentido contrario ApAthy, Peter, Schutz, des Ersitzungbesitzes durch die actio Publiciana?, en Studi Sanfilippo (Milano, Giuffrè, 1982), I, p. 33.

${ }^{13}$ Cabía, sin embargo, el recurso a la acción publiciana (principal herramienta, como veremos, de protección de estos poseedores) cuando el poseedor había adquirido de un menor sin 
pudo considerar legítimo en el momento de la adquisición (buena fe) ${ }^{14}$.

\section{Supuestos de propiedad pretoria}

$\mathrm{Si}$, por tanto, afirmamos que el propietario pretorio debe haber adquirido de buena fe mediante un título válido ¿en qué supuestos no será un auténtico propietario civil? Encontramos dos casos típicos de adquirentes que no llegan a ser, en derecho clásico, propietarios: el comprador a non domino y el que adquiere una res mancipi con defecto de forma. Los analizaremos por separado.

\section{a) adquirente a non domino}

La adquisición a non domino es el primer caso de propiedad pretoria y el que continúa produciéndose en la actualidad. Tanto la compraventa como la donación y la sucesión hereditaria son procedimientos de adquisición derivativa en los que el derecho del adquirente depende del que realmente tuviera el transmitente, en aplicación del aforismo "nemo dat quod non habet, nemo plus iuris ad alium transferre potest quam ipse habet".

Para que un adquirente a non domino merezca la protección especial que le otorga el derecho deben concurrir dos circunstancias: la primera, que el negocio jurídico traslativo que le da acceso a la posesión sea válido, es decir que, aunque no produzca el efecto de transmitir la propiedad, reúna todos los elementos esenciales necesarios para su existencia en el mundo jurídico. Ello permitirá crear la apariencia jurídica que merecerá la protección excepcional del derecho.

Junto a ello se requiere la buena fe del adquirente, ya mencionada, que supone, en este contexto, que el accipiens, en el momento de recibir la posesión, no tenga motivos para dudar de la titularidad del transmitente ${ }^{15}$.

La compraventa a non domino es un negocio jurídico válido en nuestro derecho, y también lo era en derecho clásico, como parece desprenderse de D. 18,1,28: "Ulpianus libro 41 ad Sabinum. Rem alienam distrahere quem posse nulla dubitatio est: nam emptio est et venditio: sed res emptori auferri potest".

Neracio plantea el problema de la doble venta realizada por el poseedor no propietario, afirmando que tiene mejor derecho quien recibió primero por

saberlo. Vid. D. 6,2,7,4: "Si a minore quis emerit ignorans eum minorem esse, habet Publicianam", lo que supondría una adquisición no solo ineficaz sino también inválida por falta de capacidad de obrar.

${ }^{14}$ Como es bien sabido, en derecho clásico la buena fe necesaria para la usucapión solo se requería en el momento de la adquisición (mala fides superveniens non nocet), principio que fue sustituido por influencia del derecho canónico en la necesidad de buena fe continuada durante todo el plazo de la usucapión, lo cual modifica totalmente el supuesto de hecho de la adquisición, pues, en derecho moderno, por la propia naturaleza de la institución, el poseedor ad usucapionem no sabe que lo es, y está convencido de que es verdadero propietario.

${ }^{15}$ En este sentido, la doctrina y jurisprudencia moderna se mantiene en los términos que ya formulara Juliano en el siglo II dC, recogido en D. 6,2,7,17: 17. "Iulianus libro septimo digestorum scripsit traditionem rei emptae oportere bona fide fieri: ideoque si sciens alienam possessionem adprehendit, publiciana eum experiri non posse, quia usucapere non poterit. Nec quisquam putet hoc nos existimare sufficere initio traditionis ignorasse rem alienam, uti quis possit publiciana experiri, sed oportere et tunc bona fide emptorem ese". Vid. a.e. STS Sala $1^{\text {a }}$ de 8 de octubre de 2014 cuyo FJ $3^{\circ}$ explica que la mera convicción del adquirente de la legitimidad del título del transmitente no cubre, por sí sola, el requisito de la buena fe, puesto que dicha confianza debe basarse en criterios objetivos de diligencia. 
traditio. Sin embargo, si se produjo una venta por el verus dominus y otra por un poseedor no propietario, aunque recibiera primero quien compró del usurpador, la propiedad pertenece al comprador del propietario, si recibió también la cosa. D.19,1,31: "Neratius libro tertio membranarum. pr. Si ea res, quam ex empto praestare debebam, vi mihi adempta fuerit: quamvis eam custodire debuerim, tamen propius est, ut nibil amplius quam actiones persequendae eius praestari a me emptori oporteat, quia custodia adversus vim parum proficit. Actiones autem eas non solum arbitrio, sed etiam periculo tuo tibi praestare debebo, ut omne lucrum ac dispendium te sequatur. 1. Et non solum quod ipse per eum adquisii praestare debeo, sed et id, quod emptor iam tunc sibi tradito servo adquisiturus fuisset. 2. Uterque nostrum eandem rem emit a non domino, cum emptio venditioque sine dolo malo fieret, traditaque est: sive ab eodem emimus sive ab alio atque alio, is ex nobis tuendus est, qui prior ius eius adprehendit, hoc est, cui primum tradita est. si alter ex nobis a domino emisset, is omnimodo tuendus est'.

En el mismo sentido se pronuncia Juliano en D. 6,2,9,4: "Si duobus quis separatim vendiderit bona fide ementibus, videamus, quis magis publiciana uti possit, utrum is cui priori res tradita est an is qui tantum emit. Et Iulianus libro septimo digestorum scripsit, ut, si quidem ab eodem non domino emerint, potior sit cui priori res tradita est, quod si a diversis non dominis, melior causa sit possidentis quam petentis. Quae sententia vera est'.

Como podemos ver el problema que plantea la venta a non domino en relación con la doble venta es a quién se debe proteger, a lo que ambos autores resuelven que si los dos compradores adquirieron del mismo vendedor a non domino deberá ser protegido aquel que recibió antes la posesión, pero si uno de ellos recibió del verus dominus, será aquel el propietario civil.

No es preciso insistir aquí sobre la estructura de la emptio-venditio en derecho romano clásico: un contrato consensual en el que la entrega de la cosa y el pago del precio no eran más que el cumplimiento de obligaciones derivadas de un previo acuerdo de voluntades. Dos regulae, una de Gayo y otra de Ulpiano, lo expresan con toda claridad. Gayo en sus Instituciones 3,139 enseñaba a sus alumnos que la compraventa se contraía cuando había acuerdo sobre el precio, aunque todavía no se hubiese pagado, ni se hubiesen dado unas arras, pues lo que se daba como arras era una señal de la compraventa contraída: "Emptio et venditio contrahitur, cum de pretio convenerit quamvis nondum pretium numeratum sit ac ne arra quidem data fuerit: nam quod arrae nomine datur, argumentum est emptionis et venditionis contractae".

Por su parte Ulp. 1 ad Sabinum, D. 18,1,2,1, afirmaba que no había venta sin precio, pero que no era el pago del precio, sino el acuerdo lo que perfeccionaba una compra realizada sin documentos escritos: "Sine pretio nulla venditio est: non autem pretii numeratio, sed conventio perficit sine scriptis habitam emptionem".

Conviene observar que ambos textos se refieren al acuerdo sobre el precio y no sobre la cosa, sin duda dándolo por sentado, pero, sobre todo que los dos se cuidan en subrayar que no es el pago del precio lo que perfecciona la compraventa, sino la conventio.

Esta configuración del contrato de compraventa ha pasado a los códigos modernos y, de modo muy fiel, al Código civil español: Art. 1445: "Por el contrato de compra y venta uno de los contratantes se obliga a entregar una cosa determinada y el otro a pagar por ella un precio cierto, en dinero o signo que lo represente". Art. 1450: "La venta se 
perfeccionará entre comprador y vendedor, y será obligatoria para ambos, si bubiesen convenido en la cosa objeto del contrato, y en el precio, aunque ni la una ni el otro se hayan entregado".

\section{b) adquirente de 'res mancipi' con defecto de forma}

En derecho clásico se distingue entre res mancipi y res nec mancipi. Las primeras vienen constituidas por los fundos en suelo itálico, las servidumbres rústicas, los esclavos y los animales de tiro y carga ${ }^{16}$.

Conforme al derecho civil, estas cosas mancipi, fundamentales para la economía romana, solo pueden transmitirse por medios solemnes: mancipatio, in iure cessio $^{17}$, addictio del magistrado, herencia o legado. Sin embargo, la realidad del tráfico jurídico, como suele suceder, se impuso a la norma y en cierto momento se generalizó la transmisión de las res mancipi por medio de la traditio, con omisión de las formas establecidas ${ }^{18}$.

En puridad, la transmisión de una res mancipi sin observar las formas esenciales provocaba la ineficacia del negocio, de manera que el adquirente no se convertía en propietario del bien, que se mantenía en el patrimonio del tradens. Pero ello, siendo correcto en técnica jurídica, provocaba en la práctica una grave injusticia, puesto que la observancia de las formas legales dependía de la voluntad del vendedor, de modo que este, de manera deliberada o negligente, resultaba beneficiado por su propia actuación ilícita, vulnerando el principio que prohíbe obtener beneficio de la propia torpeza.

Por esta razón, el derecho pretorio estableció mecanismos de protección específicos para quien hubiera adquirido una res mancipi por traditio, lo que, a la postre, provocó, en nuestra opinión, la desaparición de la mancipatio, y de la distinción entre res mancipi y res nec mancipi.

${ }^{16}$ No está claro en qué momento despareció la distinción entre res mancipi y nec mancipi, pues las fuentes clásicas recogidas en la compilación justinianea lo omiten, probablemente por decisión de la comisión compiladora. Gayo se refiere a la mancipatio en Inst. 1,119 y siguientes, a propósito de la coemptio liberadora de la mujer, y con motivo de ello, explica la diferencia entre las clases de cosas. En nuestra opinión, el hecho de que el jurisconsulto explique la mancipatio como un procedimiento ficticio y no como un medio verdadero de transmisión de los bienes es un poderoso indicio de que en su época ya estaba en desuso. En sentido contrario vid. AmunÁtegui Perelló, Carlos, Origen y función de la 'mancipatio', en Revista de Estudios Histórico-Jurídicos, 33 (2011), p. 38, donde sostiene que la mancipatio tuvo una larga vigencia en el mundo romano. Vid. PÉREZ Álvarez, María Pilar, La compraventa y la transmisión de la propiedad. Un estudio histórico-comparativo ante la unificación del derecho privado europeo, en RJUAM., 14 (2006), pp. 208-209, donde alega que en los Fragmenta Vaticana (siglo IV dC) se alude constantemente a la mancipatio como medio de transmisión de las res mancipi.

${ }^{17} \mathrm{La}$ in iure cessio equivale al allanamiento actual y basa su eficacia -aún vigente- en el principio dispositivo del proceso civil. En Roma, el adquirente demandaba al transmitente con la actio reivindicatoria, quien, previo acuerdo entre las partes, se allanaba, con lo que el pretor, sin entrar a valorar la procedencia de la demanda, declaraba el dominio del comprador sobre el bien y ordenaba su entrega. Ciertamente, se trataba de un juicio simulado. Vid. art. 21.1 LEC: "Cuando el demandado se allane a todas las pretensiones del actor, el tribunal dictará sentencia condenatoria de acuerdo con lo solicitado por éste".

${ }^{18}$ Junto a ello, advierte D’Ors, en algunos casos, aunque la venta era lícita, no podía otorgarse la mancipatio, como ocurría, por ejemplo, en la venta del acreedor pignoraticio. Vid. D'Ors, Álvaro, cit. (n. 2), p. 233. 


\section{Mecanismos de protección ${ }^{19}$}

Como veremos, aunque conforme al ius civile los propietarios pretorios carecían de derechos sobre la cosa adquirida ${ }^{20}$, el derecho honorario fue creando mecanismos de protección que los acercaron, en muchos casos, a la verdadera propiedad, lo que acabó desdibujando, en derecho postclásico y justinianeo, las diferencias entre posesión y propiedad.

\section{a) interdictos}

El primer remedio de que dispone un adquirente a non domino o con defecto de forma son los interdictos posesorios, siempre que retenga la posesión o le haya sido arrebatada por la fuerza en el año inmediatamente anterior. Esta protección se extendía (en nuestra opinión) a todo poseedor, natural o civil, tanto de buena como de mala fe -con excepción de los detentadores-. Con mayor razón, se concedía a quien había entrado en posesión en virtud de un título de los que generalmente confieren la propiedad ${ }^{21}$.

Esta eficaz protección pretoria, tanto en la vertiente preventiva del interdicto de retener ${ }^{22}$ como en la reparatoria ${ }^{23}$, de recobrar, protegía al tenedor frente a la vía de hecho, pues se fundamenta, como dijimos, en la necesidad de preservar la paz social. Sin embargo, resultaba -y resulta- ineficaz frente al ejercicio de acciones procesales destinadas a despojar de la posesión al propietario pretorio, que por ello debía buscar otros mecanismos de salvaguarda.

Los interdictos posesorios aparecen mencionados en las Instituciones de Justiniano. Inst. 4,15,4: "Retinendae possessionis causa comparata sunt interdicta uti possidetis et utrubi, cum ab utraque parte de proprietate alicuius rei controversia sit et ante quaeritur, uter ex litigatoribus possidere et uter petere debeat. namque nisi ante exploratum fuerit, utrius eorum possessio sit, non potest petitoria actio institui, quia et civilis et naturalis ratio facit ut alius possideat, alius a possidente petat. et quia longe commodius est possidere potius quam petere, ideo plerumque et fere semper ingens existit contentio de ipsa possessione. commodum autem possidendi in eo est, quod, etiamsi eius res non sit qui possidet, si modo actor non potuerit suam esse probare, remanet suo loco possessio: propter quam causam, cum obscura sint utriusque iura, contra petitorem indicari solet'.

Las instituciones de Justiniano, al describir el interdicto de retener inmuebles

\footnotetext{
${ }^{19}$ Sobre las acciones para la protección de la propiedad $V i d$. Fernandez De Buján, Antonio: Derecho privado romano (10 a ed., Madrid, Ed. Iustel, 2017), pp. 399 y ss.

${ }^{20} \mathrm{Al}$ menos hasta que transcurriera el plazo de la usucapión que los convertiría en verdaderos propietarios civiles

${ }^{21}$ Advierte Justiniano en Inst. 4,15,8 que los interdictos pretorios habían caído en desuso en su época, siendo reconducidos a la jurisdicción, tal como hace hoy día la Ley de Enjuiciamiento Civil, en su artículo 250.4. "De ordine et veteri exitu interdictorum supervacuum est hodie dicere: nam quotiens extra ordinem ius dicitur, qualia sunt hodie omnia iudicia, non est necesse reddi interdictum, sed perinde indicatur sine interdictis atque si utilis actio ex causa interdicti reddita fuisset".

${ }^{22}$ D. 43,17,1 Ulpianus libro 69 ad edictum Ait praetor: "Uti eas aedes, quibus de agitur, nec vi nec clam nec precario alter ab altero possidetis, quo minus ita possideatis, vim fieri veto".

${ }^{23}$ D. 43,16,1 Ulpianus libro 69 ad edictum: Praetor ait: "Unde tu illum vi deiecisti aut familia tua deiecit, de eo quaeque ille tunc ibi habuit tantummodo intra annum, post annum de eo, quod ad eum qui vi deiecit pervenerit, indicium dabo".
} 
(uti possidetis) se refieren exclusivamente a la tenencia de la cosa, sin mencionar la posible perturbación de la posesión por inmisiones. Del mismo modo se expresan las instituciones de Gayo. Gai 4,148 ss: 148. "Retinendae possessionis causa solet interdictum reddi, cum ab utraque parte de proprietate alicuius rei controuersia est et ante quaeritur, uter ex litigatoribus possidere et uter petere debeat. cuius rei gratia comparata sunt VTI POSSIDETIS et VTRVBI. 149. Et quidem VTI POSSIDETIS interdictum de fundi uel aedium possessione redditur, VTRVBI uero de rerum mobilium possessione. 150. Et si quidem de fundo nel aedibus interdicitur, eum potiorem ese".

Por su parte, Ulpiano ad Ed., en D.43,17,3, y siguientes, se encarga de definir el ámbito material del interdicto uti posidetis, aclarando en qué casos procederá la protección interdictal y en cuáles será denegada.

D. 43,17,3: Ulpianus libro 69 ad edictum. pr. "Si duo possideant in solidum, videamus, quid sit dicendum. Quod qualiter procedat, tractemus, si quis proponeret possessionem iustam et iniustam. Ego possideo ex iusta causa, tu vi aut clam: si a me possides, superior sum interdicto, si vero non a me, neuter nostrum vincetur: nam et tu possides et ego.1. Hoc interdictum duplex est et hi, quibus competit, et actores et rei sunt. 2. Hoc interdictum sufficit ei, qui aedificare in suo probibetur: etenim videris mibi possessionis controversiam facere, qui probibes me uti mea possessione. 3. Cum inquilinus dominum aedes reficere volentem probiberet, aeque competere interdictum uti possidetis placuit testarique dominum non probibere inquilinum, ne babitaret, sed ne possideret. 4. Item videamus, si auctor vicini tui ex fundo tuo vites in suas arbores transduxit, quid iuris sit. Et ait Pomponius posse te ei denuntiare et vites praecidere, idque et Labeo scribit, aut uti eum debere interdicto uti possidetis de eo loco, quo radices continentur vitium: nam si tibi vim fecerit, quo minus eas vites vel praecidas vel transducas, vim tibi facere videtur, quo minus possideas: etenim qui colere fundum probibetur, possidere probibetur, inquit Pomponius. 5. Item videamus, si proiectio supra vicini solum non iure haberi dicatur, an interdictum uti possidetis sit utile alteri adversus alterum. Et est apud Cassium relatum utrique esse inutile, quia alter solum possidet, alter cum aedibus superficiem. 6. Labeo quoque scribit: ex aedibus meis in aedes tuas proiectum habeo: interdicis mecum, si eum locum possideamus, qui proiecto tegetur. An, quo facilius possim retinere possessionem eius proiectionis, interdico tecum sic "uti nunc possidetis eas aedes, ex quibus proiectus est?" 7. Sed si supra aedes, quas possideo, cenaculum sit, in quo alius quasi dominus moretur, interdicto uti possidetis me uti posse Labeo ait, non eum qui in cenaculo moretur: semper enim superficiem solo cedere. Plane si cenaculum ex publico aditum habeat, ait Labeo videri non ab eo aedes possideri, qui kruptas possideret, sed ab eo, cuius aedes supra kruptas essententiarum verum est hoc in eo, qui aditum ex publico habuit: ceterum superficiarii proprio interdicto et actionibus a praetore utetur. Dominus autem soli tam adversus alium quam adversus superficiarium potior erit interdicto uti possidetis: sed praetor superficiarium tuebitur secundum legem locationis: et ita Pomponius quoque probat. 8. Creditores missos in possessionem rei servandae causa interdicto uti possidetis uti non posse, et merito, quia non possident: idemque et in ceteris omnibus, qui custodiae causa missi sunt in possessionem, dicendum est. 9. Si vicinus meus in parte in pariete meo tectoria habeat et in parte sua, 'uti possidetis' mibi efficax est ut ea tollere compellatur. 10. Non videor vi possidere, qui ab eo, quem scirem vi in possessionem esse, fundum accipiam. 11. In hoc interdicto condemnationis summa refertur ad rei ipsius aestimationem. 'Quanti res est sic accipimus 'quanti uniuscuiusque interest possessionem retinere'. Servii autem sententia est existimantis tanti possessionem aestimandam, quanti ipsa res est: sed hoc nequaquam opinandum est: longe enim aliud est rei pretium, aliud possessionis". 
Los interdictos posesorios tenían en Roma una cláusula de posesión viciosa que puede reconocerse en el texto de Ulpiano recogido en D. 43,17,1: pr. Ait praetor: "Uti eas aedes, quibus de agitur, nec vi nec clam nec precario alter ab altero possidetis, quo minus ita possideatis, vim fieri veto. De cloacis hoc interdictum non dabo. Neque pluris, quam quanti res erit: intra annum, quo primum experiundi potestas fuerit, agere permittam”.

La expresión "nec vi, nec clam, nec precario ab altero" se interpreta como una excepción a la tutela interdictal, que sería denegada si el perturbador demostraba que el demandante había adquirido la posesión mediante violencia, engaño o precario respecto del demandado. De esta manera se legitimaba la violencia recuperatoria del poseedor pacífico que, durante un año desde el despojo, podía acudir a la protección interdictal o recuperar la posesión por sus propios medios sin que el usurpador pudiera solicitar interdictos. Esta violencia legítima cesaba cuando el poseedor que trataba de recuperar el bien que le había sido despojado usaba una violencia desmedida, concretada en el empleo de personas armadas (aunque fuera con palos). En ese caso, el usurpador despojado con tal violencia, podía recuperar la posesión con el interdicto unde vi armata, que carecía de la cláusula de posesión viciosa D. 43,16,1: pr. Praetor ait: "Unde tu illum vi deiecisti aut familia tua deiecit, de eo quaeque ille tunc ibi babuit tantummodo intra annum, post annum de eo, quod ad eum qui vi deiecit pervenerit, iudicium dabo".

Esta excepción objetiva a la protección interdictal, junto con la exclusión subjetiva de los detentadores, desapareció, como veremos, en la codificación española por el concurso del artículo 1651 de la Ley de Enjuiciamiento Civil de 1881 y 446 CC.

\section{b) usucapión ${ }^{24}$}

Cuando la situación aberrante de que exista un poseedor civil diferente del propietario se prolonga en el tiempo, el derecho opta por consolidar la apariencia, haciendo propietario a quien ejercita de hecho el dominio, expropiando consecuentemente al verus dominus ${ }^{25}$. D. 41,3,3 "Modestinus libro quinto pandectarum. Usucapio est adiectio dominii per continuationem possessionis temporis lege definiti. La usucapión es por tanto un modo de adquirir la propiedad que se configura como mecanismo de resolución de la discrepancia entre la realidad jurídica y su apariencia.

Tradicionalmente se esgrime un doble fundamento para una institución que supone la expropiación al legítimo propietario y el apoderamiento a quien posee de manera ilegítima: Por un lado, se destaca la necesidad de seguridad jurídica que lleva a consolidar una situación pacífica que se prolonga en el tiempo, dotando así de confianza a quienes se apoyan en la apariencia de titularidad que entraña la posesión pública de un bien. Por otro lado, siguiendo las teorías de Ihering,

${ }^{24}$ D. 41,3

${ }^{25}$ La usucapión es considerada por la doctrina como un modo de adquirir la propiedad a través de la posesión con ciertos requisitos. Es un modo originario a pesar de que la cosa tuviera un propietario anterior porque el dominio del usucapiente no deriva de la titularidad del propietario usucapido, de manera que las cargas y limitaciones del anterior propietario no se traspasan al nuevo. Verda y Beamonte, José Ramón, La usucapión, en SERra Rodríguez, Adela, Derecho civil, III: Derechos reales (5 ${ }^{\mathrm{a}}$ ed., Tirant, Valencia, 2019), p. 118. 
se sostiene que los derechos subjetivos (en este caso la propiedad) se confieren a los sujetos para que sean ejercidos y la inacción del verus dominus durante un tiempo prolongado refleja cierta negligencia o una suerte de abandono presunto que legitimaría la desposesión ${ }^{26}$.

Para que ello se produzca es necesario, salvo en los casos de extraordinaria prescripción, que el poseedor civil ostente un título válido, pero ineficaz conforme al cual haya entrado, de buena fe, en posesión del bien como propietario, es decir, que sea un propietario pretorio ${ }^{27}$. D. 41,3,10 Ulpianus libro 16 ad edictum. pr. "Si aliena res bona fide empta sit, quaeritur, ut usucapio currat, utrum emptionis initium ut bonam fidem habeat exigimus, an traditionis. Et optinuit Sabini et Cassii sententia traditionis initium spectandum".

Los plazos de usucapión en derecho clásico eran muy breves (un año para bienes muebles y dos para inmuebles) lo que sugiere que la necesidad de convalidar adquisiciones defectuosas pudo ser muy elevada y que el sistema normativo prefería garantizar la seguridad jurídica frente al derecho del verus dominus. En las provincias se aplicó una forma especial de usucapión llamada longi temporis praescriptio, en la cual la bona fides y el iustus titulus se refundían en un solo requisito llamado iustum initium possessionis y exigía plazos más largos (diez años entre presentes y veinte entre ausentes) ${ }^{28}$. No producía la adquisición del dominio (efecto positivo) como la usucapio (y por tanto el prescribiente, si perdía la posesión de la cosa prescrita no podía reivindicarla), sino una excepción del prescribiente contra una eventual reclamación del dueño (efecto negativo). En derecho postclásico se estableció un sistema extraordinario de adquisición de la propiedad, llamado longissimi temporis praescriptio, por el transcurso del tiempo (treinta o cuarenta años, según el momento histórico) sin necesidad de iustum initium possessionis (buena fe y justa causa $)^{29}$.

${ }^{26}$ Verda y Beamonte, José Ramón, cit. (n. 25), p. 118, disiente de este fundamento y lo remite exclusivamente a la necesidad de consolidar la apariencia jurídica en aras de la seguridad del tráfico. Por su parte, Díez Picazo sostiene esta postura afirmando que, si el fundamento de la usucapión fuera una cierta p r e s u n c i ó n d e a b a n d o n o, bastaría con acreditar que no fue posible defender el dominio para que el propietario anterior impugnara la adquisición del usucapiente. DíEz Picazo, Luis, Sistema de derecho civil (Tecnos, Madrid, 2005), III, p. 126.

${ }^{27}$ Fuenteseca Degeneffe considera, sin embargo, que la usucapio nunca convalidaba la adquisición a non domino, puesto que el adquirente no ejercía el usus al no haber recibido la cosa del verus dominus. En opinión de esta autora, la función de la usucapio era eximir de prueba a quien había adquirido un bien más allá de los plazos establecidos, descartando la opinión de Casinos Mora, según la cual la prohibición de usucapir cosas ajenas se estableció mediante la lex Atinia (197 aC). En nuestra opinión, la citada Lex Atinia prohibió la usucapión de res furtivae, no de cualquier cosa ajena. Fuenteseca DegenefFe, Margarita, La exclusión del comprador a non domino de la usucapio, en RIDROM., Revista Internacional de Derecho Romano, 15 (2015), p. 10.

${ }^{28}$ Art. 1957 CC.

${ }^{29}$ Art. 1959 CC.

La acción publiciana es un tema clásico en derecho romano, tratado por los más grandes autores. Vid., entre otros, BuRDESE, Alberto, Editto publiciano e funzioni della compravendita romana, en Estudios en homenaje al profesor Francisco Hernández-Tejero (Madrid, 1992), II, pp. 81-89; WuBbE, Felix, Quelques remarques sur la fonction et l'origine de l'action publicienne, en RIDA., 8 (1961), pp. 417-440; Gallo, Federico, s.v. Actio publiciana in rem, NNDI., (Torino, 1957), I, pp. 267-270; 
En derecho justinianeo se refundieron las tres instituciones anteriores, admitiendo, para el cómputo del tiempo, tanto la successio possessionis como la accessio possessionis. Se exigían los mismos requisitos que la usucapio clásica, aunque no se consideraban usucapibles las cosas del Fisco, ni las de la Iglesia. Para bienes muebles se estableció un plazo de tres años; para bienes inmuebles se exigía un plazo de diez años entre presentes y veinte años entre ausentes. Junto a ellas se estableció una forma extraordinaria en la que se exigía la buena fe inicial pero no la justa causa y requería que la posesión durara treinta años en general.

Una vez transcurrido el plazo de usucapión, con la concurrencia del resto de requisitos, la adquisición a non domino o con defecto de forma, queda convalidada, y el adquirente es, de pleno derecho, propietario civil. Los remedios específicos que veremos a continuación eran efectivos, por tanto, mientras transcurría el plazo de la usucapión o en los casos en que ésta no era posible.

\section{c) exceptio rei vendita et tradita}

Cuando el propietario pretorio era demandado con la actio reivindicatoria, no podía oponer el dominio porque, conforme al derecho civil, no era propietario mientras no transcurriera el plazo de la usucapión. Sin embargo, el pretor concedía al demandado una exceptio por la que defendía haber adquirido mediante traditio la posesión de la cosa (exceptio rei vendita et tradita).

Dicha excepción sería suficiente para neutralizar la intentio de quien no pudiera acreditar haber adquirido el bien o no tuviera un título que invalidara la adquisición del propietario pretorio. Sin embargo, si el demandante tiene un título de propiedad puede tratar de invalidar la exceptio mediante una replicatio iusti dominii que destruiría la argumentación del propietario pretorio, salvo que el título de adquisición del demandado sea precisamente una venta por traditio de una res mancipi en la que, al no haberse respetado las formalidades (mancipatio, in iure cessio) el vendedor-demandante siga siendo propietario civil. En ese caso, la replicatio iusti dominii sería invalidada por una duplicatio doli que dejaría al actor sin argumentos.

Por el contrario, en el caso de adquisición a non domino, el demandado no puede alegar su adquisición frente a la propiedad civil del demandante, pues el título de adquisición del propietario pretorio es inoponible al verus dominus, que actúa aquí como demandante.

Bonfante, Pietro, L'az̧one publiciana nel diritto civile, en Scritti giuridici varii, II: Proprietà e servitù (Torino, 1918), pp. 389-438; Él mismo, L'editto publiciano, en Scritti giuridici varii, II: Proprietà e servitù (Torino, 1918), pp. 439-449; FEENSTRA, Robert, Action publicienne et preuve de la propriété. Principalement d'apres quelques romaines du moyen âge, en Mélanges Philippe Meylan (Lausanne, Imprimerie Central, 1963), I, pp. 91-110; Di LeLLA, Luigi, Formulae ficticiae. Contributo allo studio di la reforma giudiziaria di Augusto (Napoli, Ed. Jovene, 1984), pp. 67-127; VACCA, Letizia, Osservazioni in tema di actio publiciana e acquisto a non domino, en PIRO, Isabella (a cura di) Scritti per Alessandro Corbino (Tricase, 2016), VII, pp. 317-337; SAnsón Rodríguez, María Victoria, Algunas observaciones sobre la función originaria de la acción publiciana, en Anales de la Facultad de Derecho. Universidad de La Laguna, 14 (1997), pp. 135-154; FuenteseCa DegenefeE, Margarita, Proprietas, possessio y actio publiciana, en Torrent Ruíz, Armando (coord.), Actas del II Congreso Internacionaly V Iberoamericano de Derecho Romano: Los derechos reales, (Madrid, Edisofer, 2001), pp. 415-436 


\section{d) acción publiciana ${ }^{30}$}

Si el propietario pretorio perdía la posesión, no podía ejercitar la vindicatio para reclamarla, ya que no era un verdadero propietario civil. Como ya hemos señalado, el propietario pretorio, como poseedor, podría utilizar los interdictos de retener y de recobrar. Sin embargo, si transcurría un año desde el despojo o si el usurpador alegaba alguna clase de título posesorio, el adquirente quedaba desprovisto de remedio procesal que le permitiera recuperar la posesión.

Por ello se concedió una actio utilis ficticia in $\mathrm{rem}^{31}$ que protegía al propietario pretorio como si ya fuera dueño ${ }^{32}$. La acción se presenta como una vindicatio utilis, es decir, como una variante de la reivindicatoria en la que se fingía que el demandante era ya propietario por el transcurso del plazo de la usucapión. De este modo, el propietario pretorio que se veía despojado de la cosa podía recuperarla del actual poseedor, siempre que la cosa fuera identificable ${ }^{33}$.

La acción publiciana nació como una forma de protección a los llamados propietarios pretorios o bonitarios ${ }^{34}$, es decir, aquellos que aún no habían adquirido la propiedad, pero que poseían como si fuesen auténticos propietarios ${ }^{35}$. Se trataba por tanto de poseedores ad usucapionem que, una vez cumplido el plazo establecido, se convertirían en propietarios civiles por efecto de la usucapión ${ }^{36}$. Debe aquí recordarse que en derecho romano la buena fe necesaria para la usucapión sólo se tiene en cuenta en el momento de la adquisición, por lo que -a diferencia del derecho civil moderno- el poseedor ad usucapionem podía ser perfectamente consciente del defecto de su título de adquisición.

La acción triunfaba frente a cualquier poseedor que no tuviera un título legítimo de posesión, incluso frente al verdadero propietario si se trataba de una venta por traditio de res mancipi, ya que la exceptio iusti dominii del demandado (propietario civil, a fin de cuentas) podía neutralizarse con una replicatio rei venditae et traditae, frente a la que el vendedor no podía oponer nada. Por el contrario, si el deman-

\footnotetext{
${ }^{30}$ D’Ors, Álvaro, cit. (n. 2), p. 233.

${ }^{31}$ Ibíd.

${ }^{32}$ Esta es la tesis admitida de forma mayoritaria por la romanística. Vid. BONFANTE, Pietro, L'editto publiciano, en Scritti giuridici varii (Torino, U.T.E.T, 1926), II, p. 399. En sentido contrario, vid. WuBBE, Felix, Quelques remarques sur la fonction et l'origine de l'action publicienne, en RIDA., 8 (1961), pp. 422 ss. que defiende una definición más amplia del sujeto activo de la acción publiciana.

${ }^{33}$ Resulta difícil entender la necesidad de crear esta acción ficticia para proteger al candidato a usucapión a la vista de lo exiguo de los plazos establecidos en derecho clásico para la prescripción adquisitiva (un año para muebles, dos para inmuebles). Es posible que la acción se creara para proteger adquirentes que, reuniendo los requisitos de la usucapión, no pudieran acceder a ella, como podría ser el caso de los concesionarios del ager publicus.

${ }^{34}$ La génesis de la acción publiciana en cuanto a los casos inicialmente protegidos por ésta, ha suscitado un encendido debate doctrinal, que puede examinarse con detalle en SANSÓN Rodríguez, María Victoria, cit. (n. 30), pp. 142 ss.

${ }^{35}$ Se les requería por tanto los mismos presupuestos que exige la usucapión (res habilis, iustus titulus, possessio y fides), si bien, como precisa Pérez Álvarez, la buena fe se exigía no solo en el momento del contrato sino también en el de la traditio. Pérez Álvarez, María Pilar, La acción publiciana y la protección del “mejor derecho a poseer", en Revista General de Derecho Romano, 30 (2018), p. 10.

${ }^{36}$ Así lo considera la mayoría de la doctrina. Vid. SAnsón Rodríguez, María Victoria, cit. (n. 30), p. 146.
} 
dante había adquirido a non domino y el actual poseedor era el propietario civil, la intentio sería neutralizada con una exceptio iusti dominii del verdadero propietario, frente a la que el actor no podía oponer nada, pues el demandado no le había vendido el bien y su título de adquisición le era inoponible.

Conocemos la acción publiciana, a través del Digesto ${ }^{37}$, por las referencias de los principales juristas clásicos, particularmente, Ulpiano: D. 6,2,1 Ulpianus libro 16 ad edictum pr. Ait praetor: "Si quis id quod traditur ex iusta causa non a domino et nondum usucaptum petet, iudicium dabo"381. Merito praetor ait "nondum usucaptum": nam si usucaptum est, habet civilem actionem nec desiderat honorariam. Sed cur traditionis dumtaxat et usucapionis fecit mentionem, cum satis multae sunt iuris partes, quibus dominium quis nancisceretur? Ut puta legatum".

También aparece descrita la acción publiciana en las Instituciones de Gayo. Gai. 4,36 "(Eiusdem generis est Publiciana actio). Datur autem haec actio ei, qui ex iusta causa traditam sibi rem nondum usucepit: eamque amissa possessione petit. nam quia non potest eam ex iure Quiritium suam esse intendere, fingitur rem usucepisse, et ita quasi ex iure Quiritium dominus factus esset, intendit hoc modo: IVDEX ESTO. SI QVEM HOMINEM AVLVS AGERIVS EMIT ** EI TRADITVS EST, ANNO POSSEDISSIT TVM SI EVM HOMINEM, DE QVO AGITVR EIVS EXIVRE QVIRITIVM ESSE OPORTERET et reliqua".

El origen de la acción publiciana, lo encontramos en el pretor Quinto Publicius $^{39}$, aunque no conocemos referencias a la misma anteriores a $\mathrm{Neracio}^{40}$ (D. 6,2,9,3 y 6,2,17), lo que ha llevado a algunos autores a situar su origen en la primera centuria de nuestra Era" ${ }^{41}$. D. 6,2,9 Ulpianus libro 16 ad edictum I. "Item si hereditatem emero et traditam mibi rem hereditariam petere velim, Neratius scribit esse publicianam". D. 6,2,17 "Neratius libro tertio membranarum. Publiciana actio non ideo comparata est, ut res domino auferatur: eiusque rei argumentum est primo aequitas, deinde exceptio 'si ea res possessoris non sit': sed ut is, qui bona fide emit possessionemque eius ex ea causa nactus est, potius rem habeat'.

Advierte, sin embargo, Ulpiano, en D.6,2,9,5 que no cabe la acción respecto de las cosas que no se pueden enajenar, ya que indica que en esos casos el pretor no protege a nadie. D. 6,2,9 Ulpianus libro 16 ad edictum. 5. "Haec actio in his quae usucapi non possunt, puta furtivis vel in servo fugitivo, locum non habet".

${ }^{37}$ Advierte Pérez Álvarez, María Pilar, La acción, cit. (n. 35), p. 8, de que, conforme a la mayoría de la doctrina, todo el capítulo 6,2 del Digesto fue interpolado por la comisión justinianea.

${ }^{38}$ Sorprende que en la regulación contenida en D.6,2 sobre la acción publiciana no se mencione el supuesto de la adquisición de res mancipi con defecto de forma. La explicación tradicional es que la comisión justinianea borró todo rastro sobre la distinción entre res mancipi y nec mancipi, y por tanto, sobre la mancipatio, pues dicha institución se encontraba ya en desuso en su tiempo. Sin embargo, en nuestra opinión, sería defendible la hipótesis de que en tiempos de Ulpiano ya no estuviera vigente tal distinción, por lo que el jurista no se ocupara de dicho supuesto. En sentido contrario, se puede citar la referencia de Gayo (Gai. 4,36, vid. infra) a la acción publiciana, que sí podría contener un supuesto de traditio de una res mancipi.

${ }^{39}$ Año 67 aC.

${ }^{40}$ Siglo I dC.

${ }^{41}$ Vid. Cuesta SAenz, José María, La acción publiciana (Madrid, Montecorvo, 1984), p. 57. D’Ors añade que Cicerón no habla de esta acción. D’Ors, Álvaro, cit. (n. 2), p. 233. 
Como queda dicho, el demandante de la acción publiciana debía haber adquirido la posesión mediante un título válido para la transmisión del dominio: D. 6,2,3 Ulpianus libro 16 ad edictum. pr. Sunt et aliae pleraeque. "1. Ait praetor: "Ex iusta causa petet." Qui igitur iustam causam traditionis habet, utitur publiciana: et non solum emptori bonae fidei competit publiciana, sed et aliis, ut puta ei cui dotis nomine tradita res est necdum usucapta: est enim iustissima causa, sive aestimata res in dotem data sit sive non. Item si res ex causa indicati sit tradita".

D. 6,2,4 Paulus libro 19 ad edictum. Vel solvendi causa.

Incluida, obviamente, la adjudicación de la cosa en sentencia: D. 6,2,7. Ulpianus libro 16 ad edictum. pr. "Sed et si res adiudicata sit, publiciana actio competit".

Tratándose de un adelanto de la usucapión, el solicitante de la acción debía acreditar -como en aquella- su buena fe en el momento de la adquisición de la posesión

D. 6,2,7. Ulpianus libro 16 ad edictum. 11. "Praetor ait: 'Qui bona fide emit.' Non igitur omnis emptio proderit, sed ea, quae bonam fidem habet: proinde hoc sufficit me bonae fidei emptorem fuisse, quamvis non a domino emerim, licet ille callido consilio vendiderit: neque enim dolus venditoris mibi nocebit'.

Se trataba en definitiva de una acción reivindicatoria ficticia en la cual, el adquirente de buena fe que aún no había cubierto el plazo de la usucapión, podía reclamar la posesión como si ya hubiera usucapido frente a cualquiera salvo el verus dominus.

D. 6,2,16. Paulus notum ad Papiniani libro decimo quaestionum. Exceptio iusti dominii publicianae obicienda est.

\section{BREVE APUNTE SOBRE LA PROTECCIÓN DEL PROPIETARIO PRETORIO} EN DERECHO CIVIL ESPAÑOL

\section{Interdictos}

Ya se ha indicado anteriormente que, en opinión de la doctrina civilística española, el Código Civil de 1889 elimina la distinción entre poseedores y detentadores al establecer, en el artículo 446 que "Todo poseedor tiene derecho a ser respetado en su posesión", extendiéndose por tanto la protección interdictal a todo aquel que tenga en su poder una cosa por cualquier motivo. Junto a ello, se suele afirmar que en el interdicto posesorio moderno desparece la cláusula de posesión viciosa.

Por su parte, el artículo 441 CC veta expresamente el ejercicio de la violencia para adquirir la posesión, lo que parece excluir la violencia legítima recuperatoria que permitía al poseedor pacífico la regulación romana: Artículo 441: “En ningún caso puede adquirirse violentamente la posesión mientras exista un poseedor que se oponga a ello. El que se crea con acción o derecho para privar a otro de la tenencia de una cosa, siempre que el tenedor resista la entrega, deberá solicitar el auxilio de la autoridad competente".

La cuestión, a nuestro juicio, no es tan sencilla, pues el concurso de los artículos 441, 444, 445 y 460.4 CC podría dar lugar a una interpretación concorde con la tradición histórica que supondría que el usurpador no es considerado poseedor (pues no se adquiere la posesión por la fuerza), careciendo de protección interdictal, lo que legitimaría al verdadero poseedor (ahora expoliado), para que durante 
un año, ejerciera la violencia en la recuperación de su posesión, sobre todo tras la desregulación de los interdictos que supuso la LEC 1/2000.

La propia dicción del artículo 444 CC (actos meramente tolerados y los ejecutados clandestinamente... o con violencia) reproducen las palabras del pretor en la fórmula del interdicto (nec vi, nec clam, nec precario). La mayoría de la doctrina, en cambio, interpreta estos artículos en el sentido de sostener que el despojado retiene la posesión con el animus mientras que el espoliador es poseedor con el corpus (lo cual contradice el tenor literal del 445), y ambos están legitimados para interponer los interdictos, excluyéndose, durante un año, la posesión del despojante del cómputo de la usucapión.

El régimen jurídico que con ello se consigue es la consideración de que desde el momento del despojo el usurpador es poseedor, aunque el expoliado esté legitimado para el interdicto y siga usucapiendo durante un año, y no puede, en ningún caso, acudir a la violencia para recuperar su posesión. Ello quizás lleva a una solución más racional y civilizada que la clásica - en la que el despojado podía optar durante un año entre ejercitar el interdicto unde vi o recuperar la cosa usurpada por sus propios medios, usando una violencia proporcional y tasadapero quizás se aleja del sentido literal del Código Civil haciendo incomprensibles algunos preceptos. En este sentido, recuerda Manresa ${ }^{42}$, se expresaron tanto el proyecto de BGB como el Código Civil portugués (art. 486), y aunque rechaza la posibilidad de "violencia legítima del poseedor", afirma al comentar el artículo 441 CC: el poseedor legítimo a quien le ha sido arrebatada, no la pierde; el ocupante violento, no la adquiere, lo que podría justificar nuestra tesis de que debería denegarse la protección interdictal al usurpador.

\section{Acción publiciana en derecho civil español}

La evolución posterior de la acción publiciana excede con mucho del ámbito del presente trabajo. Pérez Álvarez ${ }^{43}$ afirma que a lo largo de la Edad Media el poseedor que se consideraba propietario y reclamaba la posesión ejercitaba ambas acciones de manera acumulada. Se trataría de una acumulación subsidiaria, en la que el actor afirma su dominio, pero, por si este no quedase acreditado por insuficiencia del título del transmitente, y aún no hubiera transcurrido el plazo de la usucapión, se ejercitaba subsidiariamente la acción Publiciana para reclamar la posesión". Como dice el rey sabio: Partidas 3, 10, 7: "Poner puede alguno muchas demandas contra su contendor, mostrandolas, e razonandolas todas en vno, solo que non sea contraria la vna de la otra. Ca si tales fuessen non la podria fazer".

Siguiendo a Pérez Álvarez, la acción desaparece nominalmente en la codificación ${ }^{45}$. En nuestra opinión, ello es debido a la adopción por parte del derecho

\footnotetext{
${ }^{42}$ Manresa y Navarro, José María, Comentarios al Código Civil (Madrid, Reus, 1890), IV, p. 325.

${ }^{43}$ Pérez Álvarez, María Pilar, La acción, cit. (n. 35), p. 3

${ }^{44}$ Placentino, Summa Institutionum (4,6,4): “Amice, res ista quam possides mea est et ideo directe vendico, aut si non mea est quia vendentis non fuit, quia bona fie emi publicianam intendo".

${ }^{45}$ Algunos autores, siguiendo a Aubry, Rau, Colin y Capitant, sostienen que la acción publiciana y la reivindicatoria se unifican en nuestro derecho. Vid. García VALDECASAs, Guillermo, La acción publiciana en nuestro derecho vigente, en Anuario de Derecho Civil, 1 (1948), pág. 81, quien
} 
común de la regla canónica mala fides superveniens nocet, que exige la confianza constante del poseedor en la legitimidad de su derecho durante todo el tiempo de la usucapión. Con la incorporación de dicho principio al derecho civil, desaparece la posibilidad de que un poseedor civil dude de la legitimidad de su derecho y aún así sea candidato a la usucapión, por lo que carece de sentido la protección publiciana.

Pese a ello, y a formularse por la doctrina moderna diversas posturas, la mayoría de autores ${ }^{46}$ considera que la acción publiciana subsiste en nuestro derecho ${ }^{47}$ como acción autónoma e independiente de la reivindicatoria, destinada a recuperar la posesión perdida más allá del límite de un año de los interdictos de recobrar. Se considera una acción que protege el mejor derecho a poseer (ius possidendi). Por lo general, se acepta que debe ser una posesión en concepto de dueño y hábil para usucapir ${ }^{48}$.

En nuestra opinión, para tratar de encontrar un equivalente a la acción publiciana en nuestro derecho debemos preguntarnos si los problemas jurídicos que resolvía tal acción siguen vigentes y de qué modo se resuelven en nuestra legislación.

Como sabemos, ya en época de Justiniano, la distinción entre res mancipi y nec mancipi estaba superada. La compraventa por traditio es, desde entonces, eficaz para toda clase de bienes, por lo que no encontraremos en nuestra realidad jurídica el problema de quien compró una res mancipi por traditio. Por el contrario, la traditio a non domino sigue constituyendo en la actualidad un problema jurídico que ocasiona un conflicto entre la seguridad jurídica de quien adquiere de buena fe (y los terceros que constatan la posesión civil de buena fe del adquirente) y la legitimidad del verdadero propietario, ajeno a la transmisión, y que no debería verse perjudicado por la misma. El problema, sin embargo, aun existiendo, presenta caracteres diferentes a los de la Roma clásica por cuanto en la actualidad la adquisición por usucapión requiere la confianza objetiva e invencible del poseedor de la legitimidad de su derecho durante todo el plazo de la usucapión, por lo que no encontraremos un poseedor ad usucapionem consciente de que lo es, a menos que haya transcurrido el plazo de la usucapión, en cuyo caso es verdadero propietario civil.

Por el contrario, como queda dicho, hay un supuesto en el cual un poseedor

concluye que la acción publiciana ni existe ni es necesaria en nuestro derecho. Colin, Antoine y Capitant, Henry, Curso elemental de derecho civil: II/2. De los bienes y de los derechos reales (traducida y anotada por Demófilo De Buen, Madrid, Ed. Reus, 1923), p. 1201. Pérez Álvarez, María Pilar, La acción, cit. (n. 35), p. 13, sostiene la vigencia de la acción posesoria romana invocando el artículo 251, regla $3^{\mathrm{a}}$ apartado $5^{\circ}$ de LEC de 2000, donde se establece que la cuantía se fijará según el interés económico de la demanda, cuando el proceso verse sobre la posesión y no sea aplicable otra regla de este artículo.

${ }^{46}$ Puig Brutau, Josep. Fundamentos de derecho civil (Barcelona, 1978), III, vol. 1. pp. 252- 253; DE LOS Mozos, José Luis, El principio de buena fe. (Sus aplicaciones prácticas en derecho civil español) (Barcelona, Editorial Bosch, 1965), p. 305; Cuesta SAenz, José Luis, cit. (n. 41), p. 475.

${ }^{47}$ En sentido contrario, vid. Traviesas, Miguel Manuel, Extinción y reivindicación del derecho de propiedad, en Revista de Derecho Privado (1920), p. 206

${ }^{48}$ STS de 26 de octubre de 1931 y 6 de marzo de 1956. Por su parte, la STS de 21 de febrero de 1941. Castán Tobeñas considera la acción publiciana embebida en la reivindicatoria. 
civil puede ser candidato a la adquisición prescriptiva siendo consciente de su falta de titularidad. Es la llamada prescripción extraordinaria que regula el artículo 1959 del Código Civil español. En este caso, el poseedor civil que aún no ha completado el plazo de treinta años que prescribe la norma, si se ve despojado de la posesión puede ejercitar el interdicto de recobrar durante un año desde el expolio, pero una vez transcurrido ese sólo le queda el recurso a la acción publiciana para recuperar la posesión del bien cuya propiedad aún no ha consolidado frente a quien lo posee con menor título.

Hay, por otro lado, un caso en el que el derecho opta por proteger al adquirente a non domino incluso frente al verdadero propietario: el del artículo 34 Ley Hipotecaria Española ${ }^{49}$. Como sabemos, conforme a dicha norma, quien adquiere de buena fe por título oneroso del titular registral e inscribe es protegido en su derecho frente a todos, incluso frente a quien demuestra que conforme al derecho civil extrarregistral, es propietario del bien.

\section{Conclusiones}

Primera. El problema de la adquisición a non domino, al que en la Roma clásica se añadía la traditio de res mancipi es un escollo jurídico presente en todos los ordenamientos que reconocen la propiedad privada y la compraventa como modo de transmisión de la propiedad, porque presenta un conflicto entre la legitimidad y la seguridad jurídica, especialmente cuando el adquirente ha obrado de buena fe.

El tratamiento de este problema en Roma revela la tensión entre el Ius Civile, que regulaba de manera formal la propiedad civil, y el Ius Honorarium creado por los sucesivos pretores para resolver las injusticias que la estricta aplicación del derecho civil ocasionaba en una sociedad cada vez más compleja y extensa.

La solución civil del problema de la adquisición a non domino era la usucapión, pero esta, además de la necesidad del transcurso del plazo establecido (ciertamente breve en derecho clásico) debía presentar otros problemas de aplicación que dejaría supuestos desprovistos de protección. Por ello, se hizo necesaria la creación de otras formas de protección del poseedor ad usucapionem que eximieran del transcurso del plazo o que extendieran el ámbito de protección.

Segunda. La protección pretoria del adquirente a non domino tenía un primer nivel que abarcaba a todo poseedor (natural o civil) cuya adquisición de la posesión no fuera viciosa respecto del atacante: los interdictos. Mecanismo de protección que, con ciertos matices de alcance discutible, ha llegado a nuestros días. La protección interdictal -además de estar limitada a un año desde el despojo- no dejaba de ser, como ocurre en la actualidad, una protección sumaria y provisional, que no garantiza la posesión de manera indefinida sino temporal.

Frente a demandas reivindicatorias del verus dominus o de un tercero, que considerase tener derecho sobre la cosa, el adquirente por traditio disponía de la exceptio rei tradita et vendita, mediante la cual, si acreditaba haber adquirido la cosa,

\footnotetext{
${ }^{49}$ En lo que respecta a las cosas muebles, el artículo 464 CC podría desempeñar una función similar de reconocimiento del dominio (sin necesidad de prueba, por tanto) de quien adquirió un bien mueble de buena fe.
} 
podía defenderse frente a todos, salvo frente al verdadero propietario que no había participado en la traditio y por tanto no le era oponible, conforme al principio res inter alios acta, nec nocet, nec prodest.

En el último nivel de protección, para el caso de despojo superior a un año, se creó, posiblemente en el siglo I aC, una acción reivindicatoria ficticia, mediante la cual el adquirente a non domino, o quien compró una res mancipi por traditio, podía exigir su restitución frente a cualquier poseedor, con el límite, de nuevo, del verdadero propietario que no hubiera realizado la traditio, quien podría paralizar la intentio con una exceptio iusti dominii, que seria incontestable.

Tercera. En nuestra opinión, esta protección de facto del adquirente traditario pudo influir en la desaparición de la mancipatio y, en definitiva, en la superación de la distinción entre res mancipi y nec mancipi, por un elemental principio de economía en el procedimiento contractual: si el adquirente obtiene una protección similar realice o no las formas solemnes, estas, finalmente, terminarán desapareciendo. De hecho, resulta unánime la opinión doctrinal de que la distinción entre unas y otras cosas, estaba ya superada al tiempo de Justiniano. El otro supuesto, en cambio, la adquisición a non domino queda huérfano de un remedio específico diferente de la usucapión.

Cuarta. La doctrina civilista discute de qué modo pervive, si lo hace, la acción publiciana en nuestro derecho, a falta de una mención expresa en el Código Civil español, la mayoría de autores considera que es una variante, o un complemento, de la acción reivindicatoria, útil, quizás, para el candidato a la prescripción extraordinaria del artículo 1959 CC.

Sin embargo, con la promulgación de la Ley Hipotecaria española se regula, con algunas particularidades, el caso de quien adquiere de buena fe de quien no es propietario por título oneroso y se le concede, iuris et de iure, el dominio sobre la cosa, siempre que haya confiado en la información registral y haya inscrito su derecho, otorgando, a la manera del pretor, la protección jurídica a quien, según el derecho civil, no debería ser propietario.

\section{BIBLIOGRAFÍA}

Amunátegui Perelló, Carlos: Origen y función de la 'mancipatio', en Revista de Estudios Histórico-Jurídicos, 33 (2011), pp. 37-63.

Aратнy, Pieter, Schutz des Ersitzungbesitzes durch die actio Publiciana?, en Studi Sanfilippo (Milano, Giuffrè, 1982), I, pp. 20-35.

Bonfante, Pietro, L'azione publiciana nel diritto civile, en Scritti giuridici varii, II: Proprietà e servitù (Torino, 1918), pp. 389-438.

—L'editto publiciano, en Scritti giuridici varii, II: Proprietà e servitù (Torino, 1918), pp. 439-449.

Burdese, Alberto, Editto publiciano e funzioni della compravendita romana, en Estudios en homenaje al profesor Francisco Hernández-Tejero (Madrid, 1992), pp. 81-89.

Castán Pérez Gómez, Santiago, Derecho privado romano (Madrid, 2018).

Colin, Ambrosio y Capitant, Henry, Curso elemental de derecho civil: II/2: De los bienes $y$ de los derechos reales (traducida y anotada por Demófilo de Buen, Madrid, Ed. Reus, 1923).

D’Ors, Álvaro, Derecho privado romano (Pamplona, Eunsa, 1989). 
D’Ors, Xabier, La vis en la tutela interdictal pública A propósito de una hipótesis de Labruna, en Persona y Derecho, 3 (1976), pp. 421-431.

DE los Mozos, José Luis, El principio de buena fe. (Sus aplicaciones prácticas en derecho civil español) (Barcelona, Editorial Bosch, 1965).

Díaz Bautista, Antonio y Díaz-Bautista Cremades, Adolfo Antonio, El derecho romano como introducción al derecho (Murcia, Diego Marín, 2019).

Diez Picazo, Luis, Sistema de derecho civil (Madrid, Tecnos, 2005), III.

FeEnstra, Robert, Action Publicienne et preuve de la propriété. Principalement d'apres quelques romaines du moyen âge, en Mélanges Philippe Meylan (Lausanne, Imprimerie Central, 1963), I, pp. 91-110.

Fernandez de Buján, Antonio, Derecho privado romano (10ª ed., Madrid, Ed. Iustel, 2017).

Fuenteseca Degenefee, Margarita, Proprietas, possessio y actio publiciana, en Torrent Ruíz, Armando (coord.), Actas del II Congreso Internacional y V Iberoamericano de Derecho Romano: Los derechos reales (Madrid, Edisofer, 2001), pp. 415-436.

Fuenteseca Degeneffe, Margarita, La exclusión del comprador a non domino de la Usucapio, en RIDROM. Revista Internacional de Derecho Romano, 15 (2015), pp. 1-67.

GaLlo, Federico: s.v. Actio publiciana in rem, en NNDI. (Torino, 1957), I, pp. 267-270.

Garcia Valdecasas, Guillermo, La acción publiciana en nuestro derecho vigente, en Anuario de Derecho Civil 1 (1948), pp. 78-99.

IHERING, Rudolf, La voluntad de la posesión con la crítica del método jurídico reinante (trad. Posada, A., Revista de Legislación, Madrid, 1896).

Lacruz Berdejo, José Luis, Elementos de derecho civil: III: Derechos reales (Barcelona, Bosch, 1990).

LelLA, Luigi di, Formulae ficticiae. Contributo allo studio di la reforma giudiziaria di Augusto (Napoli, Ed. Jovene, 1984).

López PÁsaro, Eduardo, Tutela sumaria de la posesión (interdicto de recobrar) (Madrid, Dykinson, 2014).

Manresa y Navarro, José María, Comentarios al Código Civil (Reus, Madrid, 1890), IV.

MeliLlo, Generoso, Interdicta e operis novi nuntiatio iuris publici tuendi gratia, en Labeo, 12 (1966), pp. 178-203.

Panero Gutiérrez, Ricardo, Derecho romano (Tirant, Valencia, 1997).

Pérez Álvarez, María Pilar, La compraventa y la transmisión de la propiedad. Un estudio histórico-comparativo ante la unificación del derecho privado europeo, en RJUAM., 14 (2006), pp. 201-248.

- La acción publiciana y la protección del "mejor derecho a poseer", Revista General de Derecho Romano, 30 (2018), pp. 1-24.

Puig Brutau, Josep, Fundamentos de derecho civil (Barcelona, 1978), III Vol. 1.

SAnsón Rodríguez, María Victoria, Algunas observaciones sobre la función originaria de la acción publiciana, en Anales de la Facultad de Derecho. Universidad de La Laguna, 14 (1997), pp. 135-152.

Traviesas, Miguel Manuel, Extinción y reivindicación del derecho de propiedad, en Revista de Derecho Privado (1920), pp. 193-208.

VAcca, Letizia, Osservazioni in tema di actio Publiciana e acquisto a non domino, en PIRO, Isabella (a cura di), Scritti per Alessandro Corbino (Tricase, 2016,) VII, pp. 317-337.

Verda y Beamonte, José Ramón, La usucapión, en Serra Rodríguez, Adela, Derecho civil, III: Derechos reales (5ª ed., Valencia, Tirant, 2019), pp. 117-138.

WubBE, Felix, Quelques remarques sur la fonction et l'origine de l'action publicienne, en RIDA., 8 (1961), pp. 417-440. 